\author{
UNIVERSIDADE DE SÃO PAULO \\ FACULDADE DE CIÊNCIAS FARMACÊUTICAS \\ Programa de Pós-graduação em Fármaco e Medicamentos \\ Área de Produção e Controle Farmacêuticos
}

\title{
Nanoemulsão catiônica contendo rifampicina para o tratamento da tuberculose ocular: preparação e caracterização físico- química e microbiológica
}

Mirla Anali Bazán Henostroza

Dissertação para obtenção do título de MESTRE

Orientadora:

Profa. Dra. Nádia Araci Bou-Chacra 


\title{
Nanoemulsão catiônica contendo rifampicina para o tratamento da tuberculose ocular: preparação e caracterização físico- química e microbiológica
}

\section{Versão corrigida}

(Versão original encontra-se na unidade que aloja o Programa de Pós-graduação)

\author{
Dissertação apresentada a Faculdade \\ de Ciências Farmacêuticas da \\ Universidade de São Paulo para \\ obtenção do título de Mestre em \\ Ciências. \\ Programa de Pós-graduação em \\ Fármaco e Medicamentos \\ Área de Produção e Controle \\ Farmacêuticos \\ Orientadora: \\ Profa. Dra. Nádia Araci Bou-Chacra
}

\section{São Paulo}

2018 
Autorizo a reprodução e divulgação total ou parcial deste trabalho, por qualquer meio convencional ou eletrônico, para fins de estudo e pesquisa, desde que citada a fonte.

Ficha Catalográfica elaborada eletronicamente pelo autor, utilizando o programa desenvolvido pela Seção Técnica de Informática do ICMC/USP e adaptado para a Divisão de Biblioteca e Documentação do Conjunto das Químicas da USP

Bibliotecária responsável pela orientação de catalogaçã̃o da publicaçẵo Marlene Aparecida Vieira - CRB - $8 / 5562$

B362n

Bazan Henostroza, Mirla Anali

Nanoemulgâo catiônica contendo rifampicina para 0 tratamento da tuberculose ocular! preparaçăo e caracterizaçăo fisico-quimica e microblologica / Mirla Anal1 Bazan Henostroza. = Săo Paulo, 2018. $127 \mathrm{p}$.

Disgertaçắo (mestrado) - Faculdade đe Ciências Farmacêuticas da Universidade đe Sẵo Paulo. Departamento de Farmácla.

Orientador: Bou-Chacra, Nadia

1. rifampicina. 2 . nanoemulgão cationica. 3 . tuberculose ocular. 4. quitosana. 5. polimixina. I. I. II. Bou-Chacra, Nadia, orlentador. 
Nome da aluna: Mirla Anali Bazán Henostroza

Título do trabalho: Nanoemulsão catiônica contendo rifampicina para o tratamento da tuberculose ocular: preparação e caracterização físico-química e microbiológica

Dissertação apresentada a Faculdade
de Ciências Farmacêuticas da
Universidade de São Paulo para
obtenção do título de Mestre em
Ciências.
Programa de Pós-graduação em
Fármaco e Medicamentos
Área de Produção e Controle
Farmacêuticos
Orientadora:
Profa. Dra. Nádia Araci Bou-Chacra

Aprovado em: 22 de maio de 2018

Banca examinadora

Prof. Dra. Priscyla Daniely Marcato Gaspari

Instituição: Universidade de São Paulo Ribeirão Preto

Prof. Dr. Newton Andréo Filho

Instituição: Universidade Federal de São Paulo - UNIFESP

Prof. Dr. André Rolim Baby

Instituição: Universidade de São Paulo 


\section{DEDICATÓRIA}

Aos meus queridos pais, Canción e Marta, por terem me ensinado o amor ao estudo e terem me dado a força para que meu sonho se tornasse realidade. Muito obrigada!!!!

Aos meus adorados irmãos Deivy e Elian, pelas energias de amor, apoio e amizade desde sempre!

À minha maravilhosa orientadora Profa. Dra. Nádia Araci Bou-Chacra, este trabalho é resultado da parceria orientador-aluno. Muito obrigada pelo incansável apoio, percepção intuitiva e sabedoria.

A todos meus familiares, em especial a meus tios Alejandro e minha tia Segundina (in memoriam) e avos Alejandrina, Crispín, Liborio e Consuelo (In memorian) que acompanharam e torceram para a conclusão de este trabalho. 


\section{AGRADECIMENTOS}

A Deus por ter orientado meus passos durante essa longa caminhada, por ter me guardado e concedido fortaleça, equilibro e sabedoria para concluir todas as etapas desse mestrado.

Aos meus amados pais Canción e Marta que deram assas firmes e fortes para voar atrás dos meus sonhos, por me oferecer suporte e consolo nas dificuldades e suas orações que me trouxeram benção para concluir essa etapa.

A minha orientadora Profa. Nádia Bou-Chacra por todos os ensinamentos, pelo incentivo no meu crescimento acadêmico, pela constante motivação a ser melhor cada dia, pela confiança e amizade. Obrigada por TUDO!!!.

À Universidade de São Paulo e ao Programa de Pós-Graduação em Fármaco e Medicamentos pela oportunidade de crescimento professional e pessoal.

À Fundação Capes pelo apoio financeiro.

A todos os professores que tive a satisfação de conhecer ao longo desta jornada acadêmica que me motivaram desde minha chegada a Faculdade de Ciências Farmacêuticas, Universidade de São Paulo.

Ao professor Humberto Gomes Ferraz e o Laboratório de desenvolvimento e inovação em farmacotécnica (DEINFAR) pelo apoio brindado durante todos os ensaios.

Ao prof. Felipe Rabelo Lourenço, pela valiosa ajuda análise estatístico dos testes microbiológicos.

Ao Prof. Mario Hirata Hirata por brindar as instalações de seu laboratório para os ensaios de concentração mínima inibitória.

A minha grande amiga Melissa que me acompanhou durante esta longa jornada.

A estagiária de Iniciação Científica Giovana quem trabalho junto comigo nos diversos testes.

Aos maravilhosos amigos do laboratório Katherine, Ivan, Megumi, Aline, Débora, Oswaldo, Christina e Eduardo pelas discussões cientificas, pela amizade e por compartilhar momentos vividos durante este período. 


\section{RESUMO}

HENOSTROZA, M.A. Nanoemulsão catiônica contendo rifampicina para o tratamento da tuberculose ocular: preparação e caracterização físicoquímica e microbiológica 2018. 127 f Dissertação (Mestrado em Ciências) Faculdade de Ciências Farmacêuticas, Universidade de São Paulo, São Paulo, 2018.

A tuberculose ocular afeta 1 a $2 \%$ dos pacientes com diagnóstico de tuberculose sistêmica. O tratamento convencional consiste na administração oral dos agentes antituberculosos. Devido às barreiras oculares, o tratamento tópico requer dose elevada e repetidas administrações para atingir efeito terapêutico no olho. Assim, a toxicidade, nos tratamentos convencionais, pode ser relevante. Considerando tais limitações, o desenvolvimento de preparações que permitam a obtenção de produtos com maior eficácia e segurança é de fundamental importância. Nesse sentido, 0 presente trabalho teve como objetivos 0 desenvolvimento, a caracterização físico-química e microbiológica de nanoemulsão contendo rifampicina (NR) revestidas empregando cloreto de quitosana (NR-Quit) e sulfato de polimixina B (NR-Poli) com potencial aplicação para o tratamento da tuberculose ocular por via tópica. A NR foi preparada empregando método por homogeneização a alta pressão e apresentou diâmetro hidrodinâmico médio (DHM), índice de polidispersão (IP), potencial zeta (PZ) e pH entre 131,0 e 137,3 nm, entre 0,19 e 0,24, entre -31,0 e -35,4 mV e entre 5,10 e 5,26, respectivamente. A eficiência de encapsulação da rifampicina, determinada por espectrofotometria UV-vis, foi de $82,5 \% \mathrm{~m} / \mathrm{v}$. Para obtenção de NR-Quit e NR-Poli foi empregado planejamento fatorial completo. Foi observada alteração do PZ de NR após adição de cloreto de quitosana de $-35,4$ para $+51,3$ $m V$. No caso da adição de sulfato de polimixina B o PZ foi alterado de $-35,4$ para $+5,5 \mathrm{mV}$. Nesse sentido, a abordagem metodológica elucidou que a concentração do cloreto de quitosana e sulfato de polimixina $B$ influenciou significativamente no potencial zeta da NR-Quit e da NR-Poli. Além disso, foi observada a relação linear entre a concentração dos agentes catiônicos empregados e o potencial zeta da NR-Quit e NR-Poli. Essas preparações, no estudo de estabilidade, mostraram aspecto visual, DHM, IP e PZ inalterados por período maior que 90 dias. Também, os valores de $\mathrm{pH}$, viscosidade e osmolalidade foram ajustados entre 4,07 e 4,55, 1,03 e 1,08 cP, 209,7 e 213,4 $\mathrm{mOsm} / \mathrm{Kg}$, respectivamente. A atividade antimicrobiana realizada frente ao Mycobacterium tuberculosis H37Rv da NR, NR-Quit, NR-Poli e solução padrão de rifampicina, determinada pela concentração mínima inibitória $(\mathrm{CMI})$, revelou $\mathrm{CMl}$ igual $0,125 \mu \mathrm{g} / \mathrm{mL}$ para todas as preparações. Tal resultado demonstrou que os processos de obtenção da nanoemulsão e do revestimento não alteraram a eficácia antimicrobiana da rifampicina. $O$ presente trabalho permitiu 0 desenvolvimento de preparações inovadoras para o tratamento da tuberculose ocular, por via tópica, com potencial maior eficácia e segurança.

Palavras-chave: rifampicina, nanoemulsão catiônica, tuberculose ocular, quitosana, polimixina 


\begin{abstract}
HENOSTROZA, M.A. Rifampicin cationic nanoemulsion for treatment of ocular tuberculosis: preparation, physical-chemical and microbiological characterization. 2018. 127 f Dissertação (Mestrado em Ciências) - Faculdade de Ciências Farmacêuticas, Universidade de São Paulo, São Paulo, 2018.
\end{abstract}

Ocular tuberculosis affects 1 to $2 \%$ of the patients diagnosed with systemic tuberculosis. The conventional treatment is the oral administration of the antituberculosis agents. Due to eye barriers, topical treatment requires high dose and repeated administrations to achieve a therapeutic effect on the eye. Thus, toxicity is a major concern in these conventional treatments. Considering these limitations, development of preparations that enable products with higher efficacy and safety is of fundamental importance. In this sense, the present work aimed preparation, physicochemical properties evaluation and microbiological characterization of the rifampicin nanoemulsion (RN) coated using chitosan chloride (RN-Chit) and polymyxin B sulfate (RN-Poly) with potential application for topical treatment of ocular tuberculosis. The RN was prepared by highpressure homogenization and present droplet mean size (DMS), polydispersity index $(\mathrm{Pdl})$, zeta potential and $\mathrm{pH}$ between 131.0 and $137.3 \mathrm{~nm}$, between 0.19 and 0.24 , between -31.0 and $-35.4 \mathrm{mV}$ and between 5.10 and 5.26 , respectively. The encapsulation efficiency of rifampicin determined of using spectrophotometric UV-vis method was $82.5 \% \mathrm{w} / \mathrm{v}$. For preparations RN-Chit and $\mathrm{RN}$-Poly factorial experimental design was employed. The change in the zeta potential of RN-Chit was observed after the addition of chitosan chloride, from 35.4 to $+51.3 \mathrm{mV}$. In the other case, an addition of polymyxin B sulfate changed the PZ from -35.4 to $+5.5 \mathrm{mV}$. Therefore, the methodological approach elucidated that the concentration of chitosan chloride and polymyxin B sulfate significantly influenced the zeta potential of RN-Chit and RN-Poly. Furthermore, the linear relationship between the concentration of cationic agents employed and the zeta potential of RN-Chit and RN-Poly was observed. These preparations, in the stability study, showed visual appearance, DMS, Pdl and PZ unchanged for a period greater than 90 days. Additionally, $\mathrm{pH}$, viscosity and osmolality values were adjusted between 4.07 and 4.55, 1.03 and $1.08 \mathrm{cP}, 209.7$ and 213.4 $\mathrm{mOsm} / \mathrm{kg}$, respectively. The antimicrobial activity against Mycobacterium tuberculosis H37Rv of RN, RN-Chit, RN-Poly and the standard solution of rifampicin, determined by the minimum inhibitory concentration (MIC), showed MIC of $0.125 \mu \mathrm{g} / \mathrm{mL}$ for all preparations. This result demonstrated that the processes of nanoemulsion preparation and coating did not affect the antimicrobial efficacy of rifampicin. The present work allowed the development of innovative preparations for the treatment of topical ocular tuberculosis with potential high efficacy and safety.

Keywords: rifampicin, cationic nanoemulsion, ocular tuberculosis, rifampicin, polymyxin 


\section{LISTA DE FIGURAS}

Figura 1 - $\quad$ Estrutura do olho (adaptado de NAKHLBAND; BARAR, 2011)

Figura 2 - Corte transversal do olho ressaltando área pre-corneal, segmento anterior e segmento posterior (adaptado de NAKHLBAND; BARAR, 2011).

Figura 3 - Diagrama do filme lacrimal com as mucinas associadas a membrana.

Figura 4 - Estrutura molecular da rifampicina (massa molar: 822,94 $\mathrm{g} / \mathrm{mol}$ ) (BURTON, et al., 2006).

Figura 5 - Evolução de publicações referentes à nanoemulsão para aplicação ocular entre 2007 a 2017. (Fonte: Scopus.com)

Figura 6 - Número de publicações por países referentes à nanoemulsão para aplicação ocular entre 2007 a 2017.

Figura 7 - Esquema da interação eletrostática entre a nanaoemulsão catiônica e cargas negativas presentes no filme lacrimal.

Figura 8 - Estrutura química da quitosana (massa molar: $1526.464 \mathrm{~g} / \mathrm{mol}$ )

Figura 9 - Estrutura química da polimixina B.

Figura 10 - Esquema da execução experimental para avaliação da eficácia antimicrobiana do Mycobacterium tuberculosis.

Figura 11 - Microscopia óptica A: rifampicina em meio aquoso. B: mistura de ácido oleico $(1,0 \mathrm{~g})$ e rifampicina $(10,0 \mathrm{mg})$. C: mistura de ácido oleico com excesso de rifampicina $>200 \mathrm{mg})$. D: mistura de ácido oleico $(1,0$ g) com 200,0

Figura 12 - Absorbância máxima da rifampicina de $50 \mu \mathrm{g} / \mathrm{mL}$ no intervalo de 200$600 \mathrm{~nm}$

Figura 13 - Espectro de varredura do solvente no intervalo de comprimento de onda entre 200 e $600 \mathrm{~nm}$.

Figura 14 - Espectro de varredura da nanoemulsão isenta de rifampicina no intervalo de comprimento de onda de 200 e $600 \mathrm{~nm}$.

Figura 15 - Curva analítica obtida na validação do método espectrofotométrico (UV-vis) para quantificação de rifampicina.

Figura 16 Grafico dos resíduos relativos ao ajuste de uma reta de regressão aos dados de absorbâncias para quantificação de rifampicina por método espectrofotométrico UV-vis

Figura 17 - Concentração de rifampicina solubilizada em 1,0 grama de lipídio

Figura 18 - - Estrutura química do ácido oleico (Massa molar: 282,46 g/mol)

Figura 19 - Estrura química do poloxamer 188. $n=80$ e $m=27$.

Figura 20 - Estrutura do polissorbato 80 (Massa molar: $1.310 \mathrm{~g} / \mathrm{mol}$ ). 
Figura 21 - Esquema simplificado da geometria da câmara de homogeneização do NanoDebee.

Figura 22 - Representação esquemática do potencial zeta

Figura 23 - Nanoemulsão contendo $0,1 \% \mathrm{~m} / \mathrm{m}$ de rifampicina imediatamente após a preparação (A) e após 210 dias (B) de armazenamento a temperatura de $20 \pm 5^{\circ} \mathrm{C}$ e acondicionamento em frascos de borosilicato âmbar. Para a fotografia a nanoemulsão foi transferida para frascos de vidro transparente.

Figura 24 - Gráfico de ionização da rifampicina em função da mudança do pH.

Figura 25 - Gráfico de cubo (planejamento fatorial $2^{3}$ ) para o potencial zeta (PZ). A resposta aparece nos vértices do cubo.

Figura 26 - Gráfico de séries temporais da avaliação do PZ da nanoemulsão contendo rifampicina $(0,1 \% \mathrm{~m} / \mathrm{m})$ revestida com cloreto de quitosana contendo as seguintes variáveis: concentração de cloreto de quitosana $(\% \mathrm{~m} / \mathrm{m})$, tempo de agitação $(\mathrm{min})$ e velocidade de agitação (rpm).

Figura 27 - $\quad$ Gráfico de Pareto para efeitos padronizados para avaliação do potencial zeta da nanoemulsão de rifampicina revestida com cloreto de quitosana contendo as seguintes variáveis: concentração de cloreto de quitosana $(\% \mathrm{~m} / \mathrm{m})$, tempo de agitação $(\mathrm{min})$ e velocidade de agitação (rpm).

Figura 28 - Gráfico de efeitos principais para avaliação do PZ da nanoemulsão contendo rifampicina revestida com cloreto de quitosana contendo as variáveis: concentração de cloreto de quitosana $(\% \mathrm{~m} / \mathrm{m})$, tempo de agitação (min) e velocidade de agitação (rpm)

Figura 29 - Gráfico de resíduos para avaliação do potencial zeta (PZ) das nanoemulsões revestidas com cloreto de quitosana considerando as variáveis: concentração de cloreto de quitosana $(\mathrm{m} / \mathrm{m})$, tempo de agitação (horas) e velocidade de agitação (rpm).

Figura 30 - Gráfico de cubo (planejamento fatorial $2^{3}$ ) para o potencial zeta (PZ). A resposta aparece nos vértices do cubo.

Figura 31 - Gráfico de series temporais para avaliação do potencial zeta da nanoemulsão de rifampicina revestida com sulfato de polimixina $B$ contendo as seguintes variáveis: Concentração de sulfato de polimixina $(\mathrm{Ul} / \mathrm{mL})$, tempo de agitação (horas) e velocidade de agitação (rpm). Comparativo com os pontos centrais.

Figura 32 - Gráfico de Pareto para efeitos padronizados para avaliação do potencial zeta da nanoemulsão de rifampicina revestida com sulfato de polimixina $B$ contendo as seguintes variáveis: Concentração de sulfato de polimixina $B(\mathrm{Ul} / \mathrm{mL})$, tempo de agitação (horas) e velocidade de agitação (rpm). 
Figura 33 - Gráfico de efeitos principais para avaliação do $P Z$ da nanoemulsão contendo rifampicina revestida com sulfato de polimixina $B$ contendo as variáveis: concentração de sulfato de polimixina $B(\mathrm{Ul} / \mathrm{mL})$, tempo de agitação (horas) e velocidade de agitação (rpm).

Figura 34 - Gráfico de resíduos para avaliação do potencial zeta (PZ) das nanoemulsões revestidas com sulfato de polimixina $B$, contendo as variáveis: concentração de sulfato de polimixina $(\mathrm{UI} / \mathrm{mL})$, tempo de agitação (horas) e velocidade de agitação (rpm).

Figura 35 - $\quad$ Análise de variância das absorbâncias. Barras com a mesma letra mostram a não existência de diferença estatisticamente significativa $(p<0,05)$.

Figura 36 - Teste de Tukey das absorbâncias a concentração de rifampicina

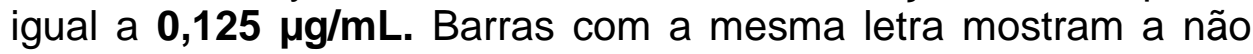
existência de diferença estatisticamente significativa (valor- $p<0,05$; $\alpha=0,05)$. 


\section{LISTA DE TABELAS}

Tabela 1 - Nanoemulsões (NE) para aplicação ocular comercializadas em

Nanoemulsões não-iônicas com potencial aplicação ocular.

Tabela 3 - Nanoestruturas catiônicas empregando quitosana com potencial aplicação ocular. NP: Nanopartícula

Tabela 4 - Nanoestruturas catiônicas empregando quitosana com potencial aplicação ocular.

Tabela 5 - Concentração das amostras de rifampicina obtidas por diluição da solução padrão de $100 \mu \mathrm{g} / \mathrm{mL}$ utilizadas para construir a curva de calibração.

Tabela 6 - Composição da nanoemulsão contendo rifampicina $0,1 \% \mathrm{~m} / \mathrm{m}$ de rifampicina.

Tabela 7

Matriz de ensaios para otimização do revestimento da nanoemulsão empregando cloreto de quitosana.

Tabela 8 - Matriz de ensaios para otimização do revestimento da nanoemulsão com sulfato de polimixina $B$

Tabela 9 - Perfil de solubilidade de rifampicina em lipídios líquidos.

Tabela 10 - Dado estatístico da curva de linearidade do método espectrofotométrico para quantificação de rifampicina.

Tabela 11 - Precisão intra-ensaio e inter-ensaio do método analítico para quantificação de rifampicina.

Tabela 12 - Exatidão recuperação de padrão do método analítico para quantificação de rifampicina

Tabela 13 Absorbâncias obtidas pelas mudanças do comprimento de onda para uma solução de $6,0 \mathrm{\mu g} / \mathrm{mL}$.

Tabela 14 - Composição das preparações preliminares contendo rifampicina.

Tabela 15 - Diâmetro hidrodinâmico médio (DHM), indice de polidispersão (IP) e potencial zeta $(\mathrm{mV})$ das nanoemulsões $0,1 \% \mathrm{~m} / \mathrm{m}$ de rifampicina após 24 horas de preparo.

Tabela 16 - Diâmetro hidrodinâmico médio (DHM) e índice de polidispersão (IP) das nanoemulsões contendo $0,1 \% \mathrm{~m} / \mathrm{m}$ de rifampicina.

Tabela 17 - Potencial zeta $(\mathrm{mV})$ das preparações contendo $0,1 \% \mathrm{~m} / \mathrm{m}$ de rifampicina

Tabela 18 - Quantidade de rifampicina encapsulado e eficiência de encapsulação em intervalo de tempo igual a 1 e 90 dias após o preparo.

Tabela 19 - Diâmetro hidrodinâmico médio (DHM), índice de polidispersão (IP) e potencial zeta (PZ) das nanoemulsões revestidas com cloreto de quitosana na matriz de ensaios do planejamento fatorial. 
Tabela 20 -

Tabela 21

Tabela 22

Tabela 23 -

Tabela 24 -

Tabela 25

Tabela 26

Teste para significância dos coeficientes codificados de regressão e índices de ajuste do modelo selecionado no ensaio para avaliação PZ das nanoemulsões de rifampicina considerando as variáveis: concentração de sulfato de polimixina $(\mathrm{Ul} / \mathrm{mL})$, tempo de agitação (horas) e velocidade de agitação (rpm).

Tabela 28 -

Tabela 29 -

Análise de variância para testar a significância da regressão para os dados obtidos no ensaio para avaliação do potencial zeta da nanoemulsão de rifampicina considerando as variáveis: concentração de cloreto de quitosana $(\mathrm{m} / \mathrm{m})$, tempo de agitação (horas) e velocidade de agitação (rpm).

Teste para significância dos coeficientes codificados de regressão e índices de ajuste do modelo selecionado no ensaio para avaliação do potencial zeta da nanoemulsão de rifampicina revestida com cloreto de quitosana considerando as variáveis: concentração de cloreto de quitosana $(\mathrm{m} / \mathrm{m})$, tempo de agitação (horas) e velocidade de agitação (rpm).

Potencial zeta das 11 preparações da matriz de ensaios do planejamento fatorial por período de 90 dias, mantidos protegidos da luz a temperatura $20 \pm 5^{\circ} \mathrm{C}$.

Potencial zeta das formulações para validação do modelo matemático do revestimento da nanoemulsão contendo rifampicina com cloreto de quitosana.

Medidas DHM, IP, PZ e pH das nanoemulsões revestidas com cloreto de quitosana.

Diâmetro hidrodinâmico médio, índice de polidispersão e potencial zeta na matriz de ensaios para o revestimento das partículas empregando sulfato de polimixina B.

Análise de variância para testar a significância da regressão para os dados obtidos no ensaio para avaliação do PZ das nanoemulsões de rifampicina considerando as variáveis: concentração de sulfato de polimixina $(\mathrm{Ul} / \mathrm{mL}$ ), tempo de agitação (horas) e velocidade de agitação

Potencial zeta das 11 preparações da matriz de ensaios do planejamento fatorial por período de 90 dias, mantidos protegidos da luz a temperatura $20 \pm 5^{\circ} \mathrm{C}$

Potencial zeta das preparações para verificação do modelo matemático para revestimento da nanoemulsão contendo rifampicina $(0,1 \% \mathrm{~m} / \mathrm{m})$ com sulfato de polimixina $B$ 
Tabela 30 - Medidas do diâmetro hidrodinâmico médio, índice de polidispersão, potencial zeta e potencial de hidrogênio das nanoemulsões contendo rifampicina revestidas com sulfato de polimixina B.

Tabela $31 \quad$ - $\quad$ Análise de variância para testar a significância da regressão para os dados obtidos no ensaio para avaliação do potencial zeta da nanoemulsão de rifampicina considerando as variáveis: concentração de cloreto de quitosana $(\mathrm{m} / \mathrm{m})$, tempo de agitação (horas) e velocidade de agitação (rpm).

Tabela 32 - $\quad$ Medidas do DHM, IP, PZ e pH das preparações revestidas com sulfato de polimixina $B$ e cloreto de cetalcônio (CCA).

Tabela 33 - Apresenta os resultados de viscosidade e osmolalidade das preparações otimizadas.

Tabela 34 - Absorbâncias da CMI das preparações isentas de rifampicina revestidas com sulfato de polimixina $B$ ou cloreto de quitosana.

Tabela 35 - Análise de variância das absorbâncias para testar a significância da regressão para os dados obtidos no ensaio de avaliação da $\mathrm{CMI}$ das nanoemulsãoes revestidas livres de rifampicina.

Tabela 36 - Absorbâncias da concentração mínima inibitória (CMI) das nanoemulsões catiônicas contendo rifampicina. 


\section{INTRODUÇÃO}

O mercado mundial de produtos farmacêuticos prevê atingir vendas de cerca de 1,5 trilhão de dólares, em 2021. Nesse mesmo ano, espera-se que o Estado Unidos mantenha a liderança do mercado de medicamentos, a nível global, com $40 \%$ desse total. Os países emergentes conquistarão, segundo essas previsões, $25 \%$ e a Europa, $12 \%$. O Brasil situa-se entre os 10 maiores mercados e perspectiva alcançar a $5^{\circ}$ posição em 2021 (INTERFAMA, 2017). O mercado total de produtos oftalmológicos foi avaliado em 24,4 bilhões de dólares, em 2016. Espera-se que esse mercado alcance os 34,3 bilhões até 2025, com taxa de crescimento anual composta de 4\% desde 2017 (TRANSPARENCY MARKET RESEARCH, 2017). Esse mercado apresenta crescimento acelerado devido ao incremento de doenças oculares como glaucoma, olho seco e desordens retinais (doenças da retina). A mudança no estilo de vida, a melhora na infraestrutura médica, as mudanças tecnológicas e o envelhecimento da população justificam esse crescimento (TRANSPARENCY MARKET RESEARCH, 2017; MARIOTTI, 2010).

As infecções oculares causadoras de perda visual foram reduzidas significativamente nos últimos 20 anos, embora o aumento de práticas cirúrgicas e o uso de lentes de contato tenham produzido maior número de infeções oculares. $O$ tratamento inadequado das infecções pode levar a perda irreversível da visão (LOPEZ-CERERO et al, 2009). Entre as infecções, a tuberculose ocular, doença negligenciada segundo o Ministério da Saúde (2016), não está incluída como alvo nesse mercado que cresce aceleradamente. Essa doença não gera lucratividade para a indústria farmacêutica e, portanto, não há interesse na pesquisa e no desenvolvimento desses medicamentos visando aprimorar sua terapêutica. Entretanto, a tuberculose ocular é problema de Saúde Pública que atinge principalmente a população de baixa renda, aquela mais vulnerável.

A incidência da tuberculose ocular é inexata, porém sabe-se que sua ocorrência alcança entre 1 e $2 \%$ dos casos de tuberculose sistêmica. Essa infecção pode afetar o segmento anterior ou posterior do olho, acometendo diversos tecidos oculares principalmente a úvea, a esclera, a retina e o epitélio pigmentar da retina (PORTELINHA et al., 2013; AREJ et al., 2016). As intervenções medicamentosas para o combate às infecções oculares estão 
estabelecidas nos guias internacionais de países como Canadá (Public Health Agency of Canada), Estados Unidos (Center for Disease Control and Prevention) e Reino Unido (United Kingdom National Guideline). Entretanto, esses guias não mencionam as intervenções para o tratamento de infecção ocular causada pelo micro-organismo Mycobacterium tuberculosis. Desse modo, o tratamento da tuberculose ocular é realizado segundo definido na terapia para o tratamento de tuberculose pulmonar. Esse tratamento inclui a administração oral de quatro antibióticos (rifampicina, isonizida, pirazinamida e etambutol), por período de 6 a 9 meses (WHO, Guideline Tuberculosis treatment, 2010; AREJ et al., 2016; FIGUEIRA, 2016; SOUISSI et al., 2017). Eventualmente, pode-se administrar topicamente anti-inflamatórios do tipo corticoesteroides (SOUISSI et al., 2017).

As formulações tópicas convencionais utilizadas na terapia ocular como colírios, suspensões e pomadas apresentam limitada biodisponibilidade dos fármacos em função dos mecanismos de proteção do olho, das suas barreiras biológicas, metabólicas e fisiológicas. As barreiras biológicas incluem o filme lacrimal, o epitélio córneano, a retina, o saco conjuntival, além das barreiras hemato-retiniana e hemato-aquosa. A barreira metabólica compreende a ação das enzimas citocromo P450 presentes nos tecidos oculares. Fator adicional que pode limitar a biodisponibilidade de fármacos administrados via ocular refere-se à absorção sistêmica desses no tecido altamente vascularizado da conjuntiva ou, ainda, via duto lacrimal. Tal fato apresenta potencial para ocasionar efeitos adversos sistêmicos potencialmente graves (CHOLKAR et al, 2013; BARANOWSKI, 2014; KASHYAP, SRINATH, 2016).

Tendo em vista superar essas limitações, as nanoemulsões têm sido consideradas como sistema de liberação promissor para uso oftálmico. Esse sistema lipidico nanoestrturado tem potencial para aumentar a eficácia terapêutica do produto minimizando seus efeitos adversos (JUDEFEIND A.; DE VILLIERS M. M., 2009; JAISWAL et al., 2015). Também, permite aumentar a biodisponibilidade de substâncias lipofílicas aumentando sua residência no local de aplicação (FENGPING; CHENGUANG, 2013). Quanto à estabilidade das nanoemulsões, o tamanho de partícula reduzido provoca significativa redução dos fenômenos de coalescência, floculação ou sedimentação durante o armazenamento (AKO-ADOUNVO et al., 2014). Adicionalmente, esses sistemas 
podem apresentar baixa viscosidade, boa aparência e versatilidade, permitindo assim obter formulações com diferente comportamento reológico, propriedades que representam benefícios biofísicos e sensoriais às preparações oftálmicas (DAULL; LALLEMAND; GARRIGUE, 2014; KASHYAP, SRINATH, 2016).

Exemplo de nanoemulsão de sucesso no mercado refere-se ao Restasis ${ }^{\circledR}$. Em 2003, a empresa Allergan (USA) lançou esse produto, a primeira nanoemulsão aniônica (ciclosporina $0,5 \mathrm{mg} / \mathrm{mL}$ ), aprovada pela FDA (Food and Drug Administration) para o tratamento de olho seco (FDA, 2003). Após uma década, em 2013, esse produto alcançou vendas de aproximadamente 1 bilhão de dólares sendo o único com venda sob prescrição médica, para o tratamento de síndrome de olho seco, nos Estados Unidos (ALLERGAN, 2013).

Com relação à nanoemulsão catiônica, a primeira foi lançada em 2008, o Cationorm ${ }^{\circledR}$ (Santen, Japão), para intervenção do olho seco moderado; comercializada inicialmente na Europa e posteriormente nos Estados Unidos sob o nome de Retaine ${ }^{\circledR}$ (DAULL; LALLEMAND; GARRIGUE, 2014). Esse produto

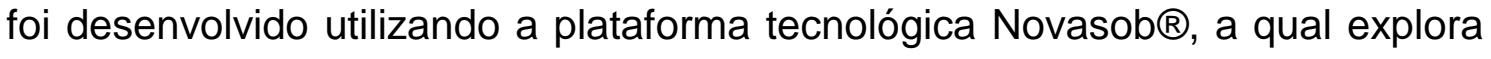
as cargas negativas da superfície ocular (OUSLER III et al., 2015). Em 2015, a plataforma Novasorb $\AA^{8}$ permitiu o lançamento no mercado europeu do produto Ikervis ${ }^{\circledR}(1 \mathrm{mg} / \mathrm{mL}$, ciclosporina $A)$, a segunda nanoemulsão catiônica, para 0 tratamento de ceratite severa. O produto mostrou ser bem tolerado, eficaz na recuperação da córnea danificada e reduziu a inflamação na superfície ocular. $O$ tratamento incluiu apenas 1 (uma) aplicação ao dia (LEONARDI et al, 2016).

Portanto, considerando o cenário mundial apresentado, torna-se interessante e inovador $o$ desenvolvimento de nanoemulsões catiônicas contendo antibiótico semissintético rifampicina para o tratamento da tuberculose ocular. Assim, busca-se contribuir para a terapêutica dessa doença por meio do desenvolvimento de produto com potencial maior eficácia e segurança, visando beneficiar a população mais vulnerável. 


\section{CONCLUSÃo}

Considerando os resultados obtidos, o presente trabalho permitiu o desenvolvimento de nanoemulsões catiônicas contendo rifampicina com potencial aplicação contra o tratamento da tuberculose ocular por via tópica; com viabilidade para serem empregados segundo a necessidade do paciente.

Com referência ao método por homogeneização a alta pressão, concluiuse que sua aplicação resultou na obtenção de nanoemulsão contendo rifampicina (NR) com adequadas características físico-químicas. Essas nanoemulsões apresentaram diâmetro hidrodinâmico médio entre 131,0 e 137,3 $\mathrm{nm}$, índice de polidispersão entre 0,19 e 0,24, potencial zeta entre -31,0 e -35,4 $\mathrm{mV}$.

No que se refere ao método analítico desenvolvido para quantificação de rifampicina, por espectrofotometria UV-vis, esse apresentou características de desempenho (linearidade, especificidade, limite de quantificação e detecção, exatidão e precisão) adequados. Adicionalmente, o método revelou eficiência de encapsulação da rifampicina igual a $82,5 \% \mathrm{~m} / \mathrm{v}$.

Quanto às nanoemulsões contendo rifampicina, após adição de cloreto de quitosana (NR-Quit), os resultados revelaram a alteração do potencial zeta de 35,4 para $+51,3 \mathrm{mV}$. Portanto, conclui-se que o método empregado permitiu a obtenção de nanoemulsão catiônica contendo rifampicina. Nesse sentido, a abordagem metodológica do processo de revestimento elucidou que a concentração de cloreto de quitosana, adicionada a nanoemulsão, influenciou significativamente no valor de potencial zeta.

Com referência a nanoemulsão contendo rifampicina após adição de sulfato de polimixina $B$, os resultados mostraram a mudança do potencial zeta de $-35,4$ para $+5,5 \mathrm{mV}$. Dessa maneira, conclui-se que o método empregado possibilitou a obtenção de nanoemulsão catiônica contendo rifampicina e sulfato de polimixina $B$, antimicrobianos hidrofóbico e hidrofílico, respectivamente. Assim, a abordagem estatística revelou que a concentração do polipeptídeo catiônico e o tempo de agitação influenciaram significativamente no valor de potencial zeta das NR. Também, apresentaram valores de $\mathrm{pH}$, viscosidade e 
osmolalidade entre 4,33 e 4,07, 1,03 e 1,07 cP, 209,7 e 213,4 mOsmol/kg, respectivamente.

A relação linear observada entre a concentração dos agentes catiônicos empregados (cloreto de quitosana e sulfato de polimixina B) e o potencial zeta permitiu concluir que é possível a manipulação das características da nanoemulsão contendo rifampicina, de acordo com o uso pretendido.

As nanoemulsões catiônicas desenvolvidas (NR-Quit e NR-poli) apresentaram estabilidade quanto ao aspecto visual e às características físicoquímicas (DHM, IP e PZ), no intervalo de 4 meses (120 dias). Também, apresentaram valores de $\mathrm{pH}$, viscosidade e osmolalidade entre 4,07 e 4,55, 1,03 e 1,08 cP, 209,7 e 213,4 mOsm/kg, respectivamente.

A avaliação da atividade antimicrobiana das preparações NR, NR-Poli, NR-Quit foi confirmada frente a solução padrão de rifampicina. Em função desse resultado pode-se concluir que o método de preparo e os componentes empregados na obtenção da nanoemulsão catiônica não alteraram a atividade antimicrobiana da rifampicina frente ao Mycobacterium tuberculosis H37Rv. 


\section{REFERÊNCIAS BIBLIOGRÁFICAS}

ABLAMOWICZ, A.F.; NICHOLS, J.J. Ocular Surface Membrane-Associated Mucins. Ocular Surface, v. 14, n. 3, p. 331-341, 2016.

AGARWAL R. et al. Liposomes in topical ophthalmic drug delivery: an update. Drug Delivery, v. 23 , n. 4, p. 1075-1091, 2014.

AGNIHOTRI, S.A.; MALLIKARJUNA N.N.; AMINABHAVI T.A. Recent advances onchitosan-based micro- and nanoparticles in drug delivery. Journal of Controlled Release, v. 100, n. 1, p. 5-28, 2004.

AHMED, et al. Potential of nanoemulsions for intravenous delivery of rifampicin. Pharmazie, v. 63, p. 806-811, 2008.

AKO-ADOUNVO, A-M. et al. Recent Patents on Ophthalmic Nanoformulations and Therapeutic Implications. Recent patents on drug delivery \& formulation, v.8, n.3, p. 193-201, 2014.

ALBERT, D.M; RAVEN, M.L. Ocular tuberculosis. Microbiology Spectrum, v. 4, n. 6, p. 1-17, 2016.

ALDRICH et al. Ophthalmic preparations. STIMULI TO THE REVISION PROCESS USP-NF, v.3, n.4, 2013.

ALI, H. H.; HUSSEIN, A. A. Oral nanoemulsions of candesartan cilexetil: formulation, characterization and in vitro drug release studies. AAPS Open, v. 3, n. 4, 2017.

ALI, M. S. et al. Preparation, Characterization and Stability Study of Dutasteride Loaded Nanoemulsion for Treatment of Benign Prostatic Hypertrophy. Iranian Journal of Pharmaceutical Research, v. 13, n. 4, p. 1125-1140, 2014.

ALIPOUR, M.; HALWANI, M.; OMRI, A.; SUNTRES, Z. E. Antimicrobial effectiveness of liposomal polymixyn B against resistant Gram-negative bacterial strains. International Journal of Pharmaceutics. v. 355, p. 293-298, 2008.

ALLERGAN 2013 ANNUAL REPORT. Disponível em:

$<$ http://www.allergan.com/miscellaneouspages/allerganpdffiles/2013annualrepo rt>. Acesso em: 10 abr. 2017.

ALLERGAN, INC. Andrew Acheampong, Diane Tang-Liu, James Chang, David Power. Methods of providing therapeutic effects using cyclosporin componentes. US20050059583 A1, 27 ago. 2004, 17 mar. 2005.

ALVES, R. et al. Thermal behavior and decomposition kinetics of rifampicin polymorphs under isothermal and non-isothermal conditions. Brazilian Journal of Pharmaceutical Sciences, v. 46, n. 2, p. 343-351, 2010. 
AMERICAN SOCIETY OPHTALMOLOGY. Ocular Tuberculosis (TB) - Asia Pacific. 2016. Disponível em: <https://www.aao.org/topic-detail/oculartuberculosis-tb-asia-pacific>. Acesso em: 04 de jun. 2017.

AMERICAN SOCIETY OPHTALMOLOGY. Ocular tuberculosis. 2014. Disponível em: <http://www.aao.org/>. Acesso em: 01 de mar. 2016.

AMMAR, H.O. et al. Development of dorzolamide hydrochloride in situ gel nanoemulsion for ocular delivery. Drug Development and Industrial Pharmacy, v. 36, n. 11, p. 1330-1339, 2010.

ANSEL, H.C.; POPOVICH, N.G.; ALLEN, L.V. Farmacotécnica: formas farmacêuticas e sistemas de liberação de fármacos. 6 ed., São Paulo: Editorial Premier, 2000, 568p.

AREJ, N.; FACHELALA, E. Choroidal tuberculoma as a presenting sign of tuberculosis. International Medical Case Reports Journal, v. 9, p. 365-368, 2016.

ARGUESO, P. et al. Association of Cell Surface Mucins with Galectin-3 Contributes to the Ocular Surface Epithelial Barrier. The Journal of Biological Chemistry, v.284, n.34, p. 23037-23045, ago. 2009.

ASASUTJARIT, R. et al. Development and Evaluation of Diclofenac Sodium Loaded-N-Trimethyl Chitosan Nanoparticles for Ophthalmic Use. AAPS PharmSciTech, v. 16, n. 5, p. $1013-1024,2015$.

ÁVILA, M. et al. As condições de saúde ocular no Brasil. Conselho Nacional de Oftalmologia. $1^{\text {a }}$ edição, 2015. São Paulo, Brasil. Disponível em: < http://www.cbo.net.br/novo/publicacoes/Condicoes_saude_ocular_IV.pdf>.

Acesso em: 27 de nov. de 2016.

BACCHI, A. et al. Comprehensive study on structure-activity relationships of rifamycins: Discussion of molecular and crystal structure and spectroscopic and thermochemical properties of rifamycin O. Journal of Medicinal Chemistry, v. 41, n. 13, p. 2319-2332, 1998.

BALASUBRAMANIAN, S.A .; PYE, D.C.; WILLCOX, M.D. Levels of lactoferrin, secretory IgA and serum albumin in the tear film of people with keratoconus. Experimental eye research, v.9, n.1, 2012.

BARANOWSKI, P. et al. Ophthalmic drug dosage forms: Characterisation and research methods. The Scientific World Journal, v. 2014, p. 1-14, 2014.

BARAR, J.; OMIDI, Y. Nanoparticles for Ocular Drug Delivery. In: KUMAR, A.; MANSOUR, H. K.; FRIEDMAN, A.; BLOUGH, E. R. (Ed.). Nanomedicine in Drug Delivery. 1st ed. London: CRC Press/Taylor \& Francis, 2013. Cap. 11. BASU, S.; DAS, T. Pitfalls in the management of TB-associated uveitis. Eye, v.24, p. 1681-1684, 2010.

BEGUM, K. et al. Characterization of Nanoemulsion Prepared from Selfemulsifying Rifampicin and its Antibacterial Effect on Staphylococcus aureus and 
Stap. epidermidis Isolated from Acne. Dhaka University Journal of Pharmaceutical Sciences, v. 14, n. 2, p. 171-177, 2015.

BISWAS, J. Ocular tuberculosis. Kerala Journal of Ophthalmology, v. 21, n. 4, p. 351-357, 2009.

BOEHM, C. Pacientes ficam cegos após infecção em mutirão de cirurgias de catarata. 2016. Disponível em: http://agenciabrasil.ebc.com.br/geral/noticia/2016-02/pacientes-ficam-cegosapos-infeccao-em-mutirao-de-cirurgias-de-catarata. Acesso em: 20 de out. 2017.

BOU-CHACRA, N. A. Sistema Lipidico Nanoestruturado para o tratamento de infecções oculares. 2015. 110p. Tese (livre-docência) - Faculdade de Ciências Farmacêuticas, Universidade de São Paulo, São Paulo, 2015.

BRASIL. Incidência da tuberculose cai $20,2 \%$ no Brasil em uma década. Disponível em: <http://portalsaude.saude.gov.br/index.php/oministerio/principal/secretarias/svs/noticias-svs/22740-incidencia-datuberculose-cai-20-2-no-brasil-em-uma-decada>. Acesso em: 3 abr. 2016.

BRASIL. Ministério da Saúde - MS. Agência Nacional de Vigilância Sanitária ANVISA. RDC № 166 de 24 de julho e 2017. Dispõe sobre a validação de métodos analíticos empregados em insumos farmacêuticos, medicamentos e produtos biológicos em todas as suas fases de produção.

BRASIL. Ministerio de Sáude. Viligância. Surto de endoftalmite aguda após cirurgias oftalmológicas em boa vista-rr. Boletim Eletrônico epidemiológico, n.5, $2006 . \quad$ Disponível em: < http://bvsms.saude.gov.br/bvs/periodicos/boletim_eletronico_epi_ano07_n05.pd f>. Acesso em: 21 de out. de 2017.

BRITO, L.A. A Cationic Nanoemulsion for the Delivery of Next-generation RNA Vaccines. Molecular Therapy, v.22, n.12, p. 2118-2129, dez. 2014.

BRON, A.J. et al. Functional aspects of the tear film lipid layer. Experimental Eye Research, v. 78, p. 347-360, 2004.

BRUNTON, L.L.; CHABNER, B.A.; KNOLLMANN, B.C. As bases farmacológicas da terapêutica de Goodman \& Gilman. 10. ed. Rio de Janeiro: McGraw Hill Interamericana, 2006.

BRUTON, L.L.; LAZO, J.S.; PARKER, K.L. eds. Goodman and Gilman's pharmacological basis of therapeutics. 11th ed. New York, NY: McGraw-Hill; 2005: 1193-1194.

BRUXEL, F. et al. Cationic nanoemulsion as a delivery system for oligonucleotides targeting malarial topoisomerase II. International Journal of Pharmaceutics, v. 416, p. 402-409, 2011. 
CAMPBELL, M.; HUMPHRIES, P. The blood-retina barrier: tight junctions and barrier modulation. Advances in experimental medicine and biology, v.762, p. 70-84, 2012.

CAMPOS, W.R.; CAMPOS, G.S.; MIRANDA, S.S. Tuberculose intraocular. Revista Brasileira Oftalmologia, v.70, n.6, p.437-451, 2011.

CHAIYASAN, W.; SRINIVAS, S. P.; TIYABOONCHAI, W. Mucoadhesive Chitosan-Dextran Sulfate Nanoparticles for Sustained Drug Delivery to the Ocular Surface. Journal of Ocular Pharmacology and Therapeutics, v. 29, n. 2, p. 200 - 207, 2013.

CHANGWONG, $\mathrm{S}$. et al. Intracellular growth and drug susceptibility of Mycobacterium tuberculosis in macrophages. Tuberculosis, v. 87, n. 2, p. 130 133, mar. 2007.

CHOLKAR, K. Novel Strategies for anterior segment ocular drug delivery. Journal of Ocular Pharmacology and Therapeutics, v.29, n. 2, p. 106-123, 2013.

CWIKLIK, L. Tear film lipid layer: A molecular level view. Biochimica et Biophysica Acta - Biomembranes, v. 1858, n. 10, p. 2421-2430, 2016.

DAS, S.; NG, W. K.; TAN, R. B. H. Are nanostructured lipid carriers (NLCs) better than solid lipid nanoparticles (SLNs): development, characterizations and comparative evaluations of clotrimazole-loaded SLNs and NLCs? European journal of pharmaceutical sciences: official journal of the European Federation for Pharmaceutical Sciences, v. 47, n. 1, p. 139-51, 30 ago. 2012.

DAULL, P. et al. Comparison of the Anti-Inflammatory Effects of Artificial Tears in a Rat Model of Corneal Scraping. Journal of Ocular Pharmacology and Therapeutics, v. 32, n. 2, p. $109-118,2016$.

DAULL, P. et al. Efficacy of a new topical cationic emulsion of cyclosporine A on dry eye clinical signs in an experimental mouse model of dry eye. Experimental Eye Research, v.153, dez. 2016.

DAULL, P.; AMRANE, M.; GARRIGUE, J.M. Novasorb® Cationic Nanoemulsion and Latanoprost: the Ideal Combination for Glaucoma Management? Journal of Eye Diseases and Disorders, v. 2, n. 1, 2017.

DAULL, P.; LALLEMAND, F.; GARRIGUE, J.S. Benefits of cetalkonium chloride cationic oil-in-water nanoemulsions for topical ophthalmic drug delivery. The Journal of pharmacy and pharmacology, v. 66, n. 4, p. 531-541, abr. 2013.

DE CAMPOS, A. M; SÁNCHEZ, A.; ALONSO, M. J. Chitosan nanoparticles: a new vehicle for the improvement of the delivery of drugs to the ocular surface. Application to cyclosporin A. International Journal of Pharmaceutics, v. 224, n. 1-2, p. 159 - 168, 2001.

DE CARVALHO, K.M.; ZIN, A. A deficiência visual nas crianças. Conselho Brasileiro oftalmologia, São Paulo, Brasil. Disponível em: $<$ http://www.jotazerodigital.com.br/cerca-de-30-mil-criancas-estao-cegas--nobrasil--por-doencas-oculares-que-podem-ser-evitadas.php >. Acesso em: 27 de nov. de 2017. 
DE LA FUENTE, M. et al. Chitosan-based nanostructures: a delivery platform for ocular therapeutics. Advanced drug delivery reviews, v. 62, n. 1, p. 100-17, 31 jan. 2010.

DEKIC, L.; PRIMORAC, M. (Ed.). Microemulsions and Nanoemulsions as Carriers for Delivery of NSAIDs. In: ČALIJA, B. Microsized and Nanosized Carriers for Nonsteroidal Anti-Inflammatory Drugs: Formulation Challenges and Potential Benefits. 1st ed. (Belgrado): Elsevier, 2017. cap. 3, p. 72.

DENNISTON, A.K.O, MURRAY, P.I. Oxford Handbook of Ophthalmology .2. ed. Oxford: Oxford University Press, 2010. 976p.

DONSì, F.; SESSA, M.; FERRARI, G. Effect of Emulsifier Type and Disruption Chamber Geometry on the Fabrication of Food Nanoemulsions by High Pressure Homogenization. Industrial \& Engineering Chemistry Research, v.51, n.22, p. 7606-7618, 2012.

DUTESCU, R.M.; PANFIL, C.; SCHRAGE, N. Osmolarity of prevalent eye drops, side effects, and therapeutic approaches. Cornea, v. 34, n.5, p. 560-566, mar. 2015.

EL-SOUSI S. et al., 2013. Hydroxypropylmethylcellulose films for the ophthalmic delivery of diclofenac sodium. Journal of Pharmacy and Pharmacology, v. 65, n. 2, p. 193 - 200, 2013.

FAPESP, UFRGS, USP. Nádia Araci Bou Chacra, Silvia Stanisçuaski Guterres, Telma Mary Kaneko, Terezinha de Jesús Andreoli Pinto. Processo de obtenção de vesículas anfifílicas positivamente carregadas, vesículas anfifílicas positivamente carregadas, suas composições farmacêuticas e/ou cosméticas e seus usos. PI0904083-08 A2. 20 out. 2009, 14 jun. 2011.

FENGPING, C.; CHENGUANG, L. Advances in nanoemulsions research. Biotechnology Bulletin, v. 0, n. 12, p. 43-48, 2013.

FERNANDEZ, D.G. Uveitis in São Paulo, Brazil: 1053 New Patients in 15 Months. Ocular Immunology and Inflammation, v.25, n.3, p. 382-387, fev. 2016.

FIGUEIRA, L. et al. Ocular tuberculosis: Position paper on diagnosis and treatment management. Revista Portuguesa de Pneumologia, v. 23, n. 1, p. 31-38, 2017.

FORRESTER, J., Dick, A.D., Mc Menamin, P.G., Roberts, F. The Eye: Basic Sciences in Practice. 3. ed. London: Elsevier Health Sciences, 2008, p. 544.

FRANCOEUR M.L.; GOLDEN G.M.; POTTS R.O. Oleic acid: its effects on stratum corneum in relation to (trans)dermal drug delivery. Pharmaceutical Research, v. 7, n. 6, p. 621-627,1990.

FU T. et al. Ocular amphotericin B delivery by chitosan-modified nanostructured lipid carriers for fungal keratitis-targeted therapy. Journal of Liposome Research, v. 27, n. 3, p. 228 - 233, 2017.

GALLO, G.G. RADAELLI, P. Rifampicin. Analytical profiles of drug substances, v.5, p. 467-513, 1976.

GAO, X. C. et al. Effects of oleic acid on the corneal permeability of compounds and evaluation of its ocular irritation of rabbit eyes. Current Eye Research, v. 39, n. 12, p. 1161-1168, 2014. 
GEORGIEV, G. A. et al. Surface Chemistry Interactions of Cationorm with Films by Human Meibum and Tear Film Compounds.International Journal of Molecular Sciences, v. 18, n. 7, 2017.

GOVINDARAJAN, B. GIPSON, I,K. Membrane-tethered mucins have multiple functions on the ocular surface. Experimental Eye Research, v.90, n.6, jun. 2010.

GREEN-CHURCH, K.B. et al. The International Workshop on Meibomian Gland Dysfunction: Report of the Subcommittee on Tear Film Lipids and Lipid-Protein Interactions in Health and Disease. Investigative Ophthalmology \& Visual Science, v.52, n.4, p.1979-1993, mar. 2011.

GUIA 2017 INTERFARMA. Dados do Setor. Brasil, 2017. Disponível em: <https://www.interfarma.org.br/guia/guia-2017/dados-do-setor/>. Acesso em: 17 out. 2017.

GUPTA, A. et al. Nanoemulsions: formation, properties and applications. Soft Matter, v. 12, p. 2826-2841, 2016.

GUPTA, B. Ocular manifestations of tubeculosis: an update. Expert Review of Ophthalmology, v. 11, n. 2, 2016.

GUZMAN-ARANGUEZ, A., ARGUESO, P. Structure and Biological Roles of Mucin-type O-glycans at the ocular surface. Ocular Surface, v. 8, n.1, p. 8-17, 2010.

HAGIGIT, T. et al. Ocular antisense oligonucleotide delivery by cationic nanoemulsion for improved treatment of ocular neovascularization: An in-vivo study in rats and mice. Journal of Controlled Release, v. 160, n. 2, p. 225-231, 2012.

HAGIGIT, T. et al. The influence of cationic lipid type on in-vitro release kinetic profiles of antisense oligonucleotide from cationic nanoemulsions. European Journal of Pharmaceutics and Biopharmaceutics, v. 70, n. 1, p. 248-259, 2008.

HAGIGIT, T. et al. Topical and intravitreous administration of cationic nanoemulsions to deliver antisense oligonucleotides directed towards VEGF KDR receptors to the eye. Journal of Controlled Release, v. 145, n. 3, p. 297305, 2010.

HAKKARAINEN, J.J. et al. Acute cytotoxic effects of marketed ophthalmic formulations on human corneal epithelial cells. International Journal of Pharmaceutics, v. 511, n. 1, p. 73-78, 2016.

HINCHEY, J. Enhanced priming of adaptive immunity by a proapoptotic mutant of Mycobacterium tuberculosis. The Journal of Clinical Investigation, v.117, n. 8, p. 2279-2288, ago. 2007.

HODGES, R. R.; DARTT, D. A. Tear film mucins: Front line defenders of the ocular surface; comparison with airway and gastrointestinal tract mucins. Experimental Eye Research, 2013.

HOLLAND, E., MANNIS, M., LEE, W. B., Ocular Surface Disease: Cornea, Conjunctiva and Tear Film. 1. ed. USA: Elsevier Health Sciences, 2013. 472 p. 
HOLLAND, E.J; MANNIS, M.J.; LEE, W.B. Filme lacrimal, anatomia, estrutura e função. Doenças da Superfície Ocular: Córnea, Conjuntiva e Filme Lacrimal. Parte 1. Elsevier. 2015.

HORNOF, M.; TOROPAINEN, E.; URTTI, A. Cell culture models of the ocular barriers. European journal of pharmaceutics and biopharmaceutics : official journal of Arbeitsgemeinschaft für Pharmazeutische Verfahrenstechnik e.V, v. 60, n. 2, p. 207-25, jul. 2005.

JAISWAL, M.; DUDHE, R.; SHARMA, P. K. Nanoemulsion: an advanced mode of drug delivery system. Biotech, v.5, p. 123-127, 2015.

JHAMB, S. S; GOYAL, A.; SINGH, P. P. Determination of the activity of standard anti-tuberculosis drugs against intramacrophage Mycobacterium tuberculosis, in vitro: MGIT 960 as a viable alternative for BACTEC 460. The Brazilian Journal of Infectious Diseases, v.18, n.3, p. 336-340, mai-jun, 2014.

JIAO, J. Polyoxyethylated nonionic surfactants and their applications in topical ocular drug delivery. Advanced Drug Delivery Reviews, v.60, n.15, dez. 2008.

JUDEFEIND A.; DE VILLIERS M. M. (Ed.). Drug Loading into and In vitro Release from Nanosized Drug Delivery Systems. In: DE VILLIERS M. M.; ARAMWIT P.; KWON G. S. Nanotechnology in Drug Delivery. 1st ed.(New York): Springer, 2009. cap. 5, p.129.

$\mathrm{KAO}, \mathrm{H} .-\mathrm{J}$. et al. Characterization of pilocarpine-loaded chitosan/Carbopol nanoparticles. Journal of Pharmacy and Pharmacology, v. 58, n. 2, p. $179-$ 186, 2006.

KARTHIK, K. et al. Effect of Different Grades of Chitosan on Physicochemical and In-vitro Release Characteristics of Acyclovir Nanoparticles for Ocular Delivery K Karthik. Research Journal of Pharmaceutical, Biological and Chemical Sciences, v. 2, n. 4, p. $79-91,2011$.

KASHYAP, Y.V.; SRINATH, P. Recent Advances in Topical Ocular Drug Delivery. Journal of Ocular Pharmacology and Therapeutics, v. 32, n. 2, p. 67-82, fev. 2016.

KASONGO, W.A. Selection and Characterization of Suitable Lipid Excipients for use in the Manufacture of Didanosine-Loaded Solid Lipid Nanoparticles and Nanostructured Lipid Carriers. Journal of Pharmaceutical Sciences, v.100, n.12, dez. 2011.

KASZUBA, M. et al. High-concentration zeta potential measurements using lightscattering techniques. Philosophical Transactions of The Royal Society A, v. 368, p. 4438-4451, 2010.

KASZUBA, M. et al. High-concentration zeta potential measurements using lightscattering techniques. Philosophical Transactions of The Royal Society A, v. 368, p. 4438-4451, 2010.

KASZUBA, M. et al. Measuring sub nanometre sizes using dynamic light scattering. Journal of Nanoparticle Research, v. 10, n. 5, p. 823-829, 2008. 
KATZER T, et al. Castor oil and mineral oil nanoemulsion: development and compatibility with a soft contact lens. Pharmaceutical Development and Technology, v. 19, n. 2, p. 232-237, 2014.

KATZER, T. et al. Castor oil and mineral oil nanoemulsion: development and compatibility with a soft contact lens. Pharmaceutical Development and Technology, v. 19, n. 2, p. 232-237, 2014.

KESAVAN, K. et al. Mucoadhesive chitosan-coated cationic microemulsion of dexamethasone for ocular delivery: in vitro and in vivo evaluation. Current Eye Research, v. 38, n. 3, p. 342-352, 2013.

KIM, H.S. et al. Evaluation of Clinical Efficacy and Safety of a Novel Cyclosporin A Nanoemulsion in the Treatment of Dry Eye Syndrome. Journal of ocular pharmacology and therapeutics, v.33, n.7, 2017.

KINNUNEN, K. et al. Cationorm shows good tolerability on human HCE-2 corneal epithelial cell cultures. Experimental Eye Research, v. 120, p. 82 - 89, 2014.

KLANG, $\mathrm{H}$. et al. Physicochemical characterization and acute toxicity evaluation of a positively-charged submicron emulsion vehicle. Journal of Pharmacy and Pharmacology, v. 46, n. 12, p. 986 - 993, 1994.

KOROLEVA, M.YU; YURTOV, E.V Nanoemulsions: the properties, methods of preparation and promising applications. Russian Chemical Reviews, v.81, n.1, p. $21-43,2012$.

KULKARNI, V.S.; SHAW, C. Preparation and Stability Testing. In: Essential Chemistry for Formulators of Semisolid and Liquid Dosages. Elsevier, 2016. cap.7, p.99-135.

LALLEMAND, F. et al. Successfully improving ocular drug delivery using cationic nanoemulsion, Novasorb. Journal of Drug Delivery, v. 2012, n. 1, p. 1-16, 9 nov. 2011.

LAM, S.M. et al. Lipidomic Analysis of Human Tear Fluid Reveals StructureSpecific Lipid Alterations in Dry Eye Syndrome. Journal of Lipid Research, v.55, n.2, p. 299-306, fev. 2014.

LEONARDI, A. et al. Efficacy and safety of $0.1 \%$ cyclosporine A cationic emulsion in the treatment of severe dry eye disease: A multicenter randomized trial. European Journal of Ophthalmology, v. 26, n. 4, p. 287-296, 2016.

LEONARDI, A. et al. Influence of different surfactants on the technological properties and in vivo ocular tolerability of lipid nanoparticles. International Journal of Pharmaceutics, v. 470, n. 1-2, 15, p. 133-140, 2014.

LERNER, T.R. Mycobacterium tuberculosis replicates within necrotic human macrophages. Journal of Cell Biology, v.216, n.3, p. 583-594, mar. 2017.

$\mathrm{LI}$, J. et al. A comparative study on the efficiency of chitosan- $\mathrm{N}$-acetylcysteine, chitosan oligosaccharides or carboxymethyl chitosan surface modified nanostructured lipid carrier for ophthalmic delivery of curcumin. Carbohydrate Polymers, v. 146, p. 435 - 444, 2016.

$\mathrm{LI}$, X. et al. Mucoadhesive dexamethasone acetate-polymyxin B sulfate cationic ocular nanoemulsion - Novel combinatorial formulation concept. Pharmazie, v. 71, n. 6, p. 327-333, 2016. 
LIN, H. R. et al. Pilocarpine-loaded chitosan-PAA nanosuspension for ophthalmic delivery. Journal of Biomaterials Science, Polymer Edition, v. 18, n. 2, p. 205221, 2007.

LIU, D. et al. Potential advantages of a novel chitosan-N-acetylcysteine surface modified nanostructured lipid carrier on the performance of ophthalmic delivery of curcumin. Scientific Reports, v.6, p. 28796, 2016.

LÓPEZ-CERERO, L.; ETXEBARRIA, J.; MENSA, J. Diagnóstico microbiológico de las infecciones oculares. Enfermedades infecciosas y Microbiología Clínica, v. 27, n. 9, p. 531-535, nov. 2009.

LIM, C. et al. Preparation and characterization of a lutein loading nanoemulsion system for ophthalmic eye drops. Journal of Drug Delivery Science and Technology, v. 36, 168-174, 2016.

LUDWIG, A. The use of mucoadhesive polymers in ocular drug delivery. Advanced Drug Delivery Reviews, v. 57, n. 11, p. 1595-1639, 2005.

MA, J.; RUBIN, B.K.; VOYNOW, J.A. Mucins, Mucus, and Goblet Cells. Chest, 2017.

MAO, G. et al. Oleic Acid Disorders Stratum Corneum Lipids in Langmuir Monolayers. Langmuir, v. 29, n. 15, p. 4857-4865, 2013.

MARIOTTI, S.P. GLOBAL DATA ON VISUAL IMPAIRMENTS 2010. World Health Organization. Genebra, Suíça. Disponível em: <http://www.who.int/blindness/GLOBALDATAFINALforweb.pdf>. Acesso em: 27 de nov. de 2017.

MASON, T.G. Nanoemulsions: formation, structure, and physical properties. Journal of Physics: Condensed Matter, v.18, p.635-666, 2006.

MEHTA, S.K.; KAUR, G.; BHASIN, K.K. Analysis of Tween based microemulsion in the presence of TB drug rifampicin. Colloids and Surfaces B: Biointerfaces, v. 60 , n. 1, p. $95-104,2007$.

MITRA, A. Ocular Transporters and Receptors their role in drug delivery. $1^{\text {st }}$ ed. Elseiver. 2013.

MONTEIRO, L. M. et al. Buparvaquone Nanostructured Lipid Carrier: Development of an Affordable Delivery System for the Treatment of Leishmaniases. BioMed Research International, v. 2017, 2017.

MONTGOMERY, D.C. Introdução ao controle estatístico da qualidade. 4. Ed. Rio de Janeiro: LTC 2004. p. 513

MORSI N, et al. Nanoemulsion-based electrolyte triggered in situ gel for ocular delivery of acetazolamide. European Journal of Pharmaceutical Sciences, v. 104, p. 302-314, 2017.

MORSI, N. et al. Nanoemulsion-based electrolyte triggered in situ gel for ocular delivery of acetazolamide. European Journal of Pharmaceutical Sciences, v. 104, p. 302-314, 2017.

NAKHLBAND, A.; BARAR, J. Impacts of nanomedicines in ocular pharmacotherapy. Biolmpacts : BI, v. 1, n. 1, p. 7-22, jan. 2011. 
NGUYEN, P.; MEYYAPPAN, M.; YIU, S.C. Applications of nanobiotechnology in ophthalmology--Part I. Ophthalmic research, v. 44, n. 1, p. 1-16, jan. 2010.

NORN, M. S. Tear fluid $\mathrm{pH}$ in normals, contact lens wearers, and pathological cases. Acta Ophthalmologia, vol. 66, n. 5, p. 485-489, 1988.

OUSLER III, G. et al. an evaluation of retaine ${ }^{T M}$ ophthalmic emulsion in the management of tear film stability and ocular surface staining in patients diagnosed with dry eye. Clinical Ophthalmology, v. 9, p. 235-243, 2015.

PANATIERI, L. F. et al. Nanoemulsions Containing a Coumarin-Rich Extract from Pterocaulon balansae (Asteraceae) for the Treatment of Ocular Acanthamoeba Keratitis. AAPS PharmSciTech, v. 18, n. 3, p. 721-728, 2017.

PARCHAND, S. et al. Intraocular Tuberculosis. Journal of Posgraduate Medicine, Education and Research, v.47, n.4, p. 193-201, 2013.

PARDEIKE. J. et al. Development of an itraconazole-loaded nanostructured lipid carrier (NLC) formulation for pulmonary application. International Journal of Pharmaceutics, v. 419, n. 1-2, p. 329-338, out. 2011.

PATHAK, CHHABRA, PATHAK, Design and development of a novel $\mathrm{pH}$ triggered nanoemulsified in-situ ophthalmic gel of fluconazole: ex-vivo transcorneal permeation, corneal toxicity and irritation testing. Drug Development and Industrial Pharmacy, v. 39, n. 5, p. 780-790, 2013.

PATHAK, M.K.; CHHABRA, G.; PATHAK, K. Design and development of a novel $\mathrm{pH}$ triggered nanoemulsified in-situ ophthalmic gel of fluconazole: ex vivo ex corneal permeation, corneal toxicity and irritation test. Drug Development and Industrial Pharmacy, v. 39, n. 5, p. 780-790, 2013.

Pharmacopeia and National Formulary (USP 35). Rockville, MD: United States Pharmacopeia Convention; 2013.

PINHEIRO, R.; PANFIL, C.; SCHRAGE, N.; DUTESCU, R.M. Comparison of the lubricant eyedrops Optive $\AA$, Vismed Multi®, and Cationorm $\AA$ on the corneal healing process in an ex vivo model. European Journal of Ophthalmology, v. 25, n. 5, p. 379-384, jun. 2015.

PORTELINHA, J. et al. Tuberculose ocular presumida. Oftalmologia, v.37, n.4 p. 227-235, dez. 2013.

POTVIN, R.; MAKARI, S.; RAPUANO, C. J. Tear film osmolarity and dry eye disease: a review of the literature. Clinical Ophthalmology, v. 9, p. $2039-2047$, 2015.

RABINOVICH-GUILATT, L. et al. Cationic vectors in ocular drug delivery. Journal of Drug Targeting, v. 12, n. 9-10, p. 623-633, 2004.

RAJASEKARAN, A. et al. A comparative review on conventional and advanced ocular drug delivery formulations. International Journal of PharmThec Research, v.2, n.1, 2010.

RASTOGI N, et al. In vitro activities of fourteen antimicrobial agents against drug susceptible and resistant clinical isolates of Mycobacterium tuberculosis and comparative intracellular activities against the virulent H37Rv strain in human macrophages. Current Microbiology, v.33, p. 167 175, 1996. 
RATHOUSKY, J. et al. A study into the self-cleaning surface propertie-The photocatalytic decomposition of oleic acid. Catalysis today, v. 161, n. 1, p. 202208, 17 mar. 2011.

ROBERT, P.Y. et al. Efficacy and safety of a cationic emulsion in the treatment of moderate to severe dry eye disease: a randomized controlled study. European Journal of Ophthalmology, v. 26, n. 6, p. 546-555, 2016.

ROMERO, G. B. et al. Development of cationic nanocrystals for ocular delivery. European Journal of Pharmaceutics and Biopharmaceutics, v. 107, p. 215222, 2016.

ROWAT, et al., Interactions of oleic acid and model stratum corneum membranes as seen by 2 H NMR International. Journal of Pharmaceutics , v. 307, p. 225231,2006 .

ROWE, R. C., SHESKEY, P. J., \& WELLER, P. J. Handbook of pharmaceutical excipients. London, Pharmaceutical Press. 2003.

RUPONEN, M., URTTI, A. Undefined Role of Mucus as a Barrier in Ocular Drug Delivery. European Journal of Pharmaceutics and Biopharmaceutics, v.96, p. 442-446, out. 2015.

SANGHVI, C. et al. Presumed tuberculous uveitis: diagnosis, management, and outcome. Eye, v.25, v.4, p. 475-480, abr. 2011.

SANTEN PHARMACEUTICAL. Products in pipline-Santen. Disponível em: $<\mathrm{http}: / /$ www.santen.com/en/rd/pdf/pipeline.pdf>. Acesso em: 20 mar. 2017.

SANTOS, J. et al. Assessing differences between Ostwald ripening and coalescence by rheology, laser diffraction and multiple light scattering. Colloid and Surfaces B Biointerfaces, v.159, p. 405-411, 2017.

SCHIRMBECK, T. et al. Endoftalmite: uma análise de 58 casos. Arquivos Brasileiros de Oftalmologia, v.63, n.1, fev. 2000.

SCHULTZ, C. Safety and Efficacy of Cyclosporine in the Treatment of Chronic Dry Eye. Ophthalmology and Eye Diseases, v.24, p. 37-42, 2014.

SEYFODDIN A. et. al., Ex vivo and In vivo Evaluation of Chitosan Coated Nanostructured Lipid Carriers for Ocular Delivery of Acyclovir. Current Drug Delivery, v. 13, n. 6, p. 923 - 934, 2016.

SHAH, K., CHAN, L.W.; WONG, T.W. Critical physicochemical and biological attributes of nanoemulsions for pulmonary delivery of rifampicin by nebulization technique in tuberculosis treatment. Drug Delivery, v.24, n.1, p.1631-1647, 2017.

SHAH, K.; CHAN, L.W.; WONG, T.W. Critical physicochemical and biological attributes of nanoemulsions for pulmonary delivery of rifampicin by nebulization technique in tuberculosis treatment. Drug Delivery, v.24, n. 1, 2017.

SHAH, K.; CHANG, L. W.; WONG, T. W. Critical physicochemical and biological attributes of nanoemulsions for pulmonary delivery of rifampicin by nebulization technique in tuberculosis treatment. Drug Delivery, v. 24, n. 1, p. 16311647, 2017.

SHARMA S, SAHNI JK, ALI J, BABOOTA S.Effect of high-pressure 
homogenization on formulation of TPGS loaded nanoemulsion of rutinpharmacodynamic and antioxidant studies. Drug Delivery, v. 22, p. 541-551, 2014.

SHARMA, A.; THAPA, B.; LAVAJU, P. Ocular tuberculosis: an update. Nepal Journal Ophthalmology, v.3, n.1, p. 52-67, jan. 2011.

SHARMA, S. Interfacial and coloidal properties of emulsified systems: pharmaceutical and biological perspective. 2014, cap.8, p.157.

SILVA, L. M. P. DA et al. Visual impairment from uveitis in a reference hospital of Southeast Brazil: a retrospective review over a twenty years period. Arquivos Brasileiros de Oftalmologia, v. 76, n. 6, p. 366-369, 2013.

SINGH, Y. et al. Nanoemulsion: Concepts, development and applications in drug delivery. Journal of Controlled Release, v.252, n.28, abr. 2017.

SOBHANI, Z. et al. Nanoparticles of Chitosan Loaded Ciprofloxacin: Fabrication and Antimicrobial Activity. Advanced Pharmaceutical Bulletin, v. 7, n. 3, p. 427-432. 2017.

SOUISSI, S.; DAVID, T.; BERAL, L. Steroid treatment in ocular tuberculosis: A double-edged sword? Corticothérapie et tuberculose oculaire : une épée à double tranchant? Steroid treatment in ocular tuberculosis: A double-edged sword? Journal français d'ophtalmologie, v. 40, p. 126-132, 2017.

SRAVANTHI, V. et al. Oleic acid nanoemulsion for nasal vaccination: Impact on adjuvanticity based immune response. Journal of Drug Delivery Science and Technology, v. 28, p. $56-63,2015$.

SUO, J. et al. Minimal Inhibitory Concentrations of Isoniazid, Rifampin, Ethambutol, and Streptomycin against Mycobacterium tuberculosis Strains Isolated before Treatment of Patients in Taiwan. American Journal of Respiratory and Critical Care Medicine, v.138, n. 4, out. 1988.

SZTRIHA, L.S. BETZ, L. Oleic acid reversibly opens the blood-brain barrier. Brain research, v. 550, n.2, jun. 1991.

TABUJEW, I; PENEVA, K. Functionalization of Cationic Polymers for Drug Delivery Applications. In: Cationic Polymers in Regenerative Medicine, 2014, p. 1-29.

TALEGAONKAR, S. et al. Design and Development of Oral Oil-in-Water Nanoemulsion Formulation Bearing Atorvastatin: In Vitro Assessment. Journal of Dispersion Science and Technology, v. 31, n. 5, p. 690-701, 2010.

TEIXEIRA, H,F. Cationic nanoemulsions as nucleic acids delivery systems. International Journal of Pharmaceutics, v.534, n. 1-2, dez. 2017.

THODE, K.; MÜLLER, R.H.; KRESSE, M. Two-Time Window and Multiangle Photon Correlation Spectroscopy Size and Zeta Potential Analysis - Highly Sensitive Rapid Assay for Dispersion Stability. Journal of Pharmaceutical Sciences, v.89, n.10, out. 2000.

TODA, R. et al. Comparison of drug permeabilities across the blood-retinal barrier, blood-aqueous humor barrier, and blood-brain barrier. Journal of 
pharmaceutical sciences, v. 100, n. 9, p. 3904-11, set. 2011.

TRANSPARENCY MARKET RESEARCH. Global Ophthalmic Drugs Market. 2017.

Disponível

em:

$<$ https://www.transparencymarketresearch.com/ophthalmic-drugs-market.html>. Acesso em: 27 de nov. de 2017.

UNITED STATES. Food and Drug Administration. Drug Approval Packages. Restasis Cyclosporine Ophthalmic Emulsion. 2003. Disponível em: $<$ https://www.accessdata.fda.gov/drugsatfda_docs/nda/2003/21-

023_Restasis.cfm>. Acesso em: 25 de mar. 2017.

URTTI, A. Challenges and obstacles of ocular pharmacokinetics and drug delivery. Advanced drug delivery reviews, v. 58, n. 11, p. 1131-5, 15 nov. 2006.

URZUA, C.A. et al. Clinical Features and Prognostic Factors in Presumed Ocular Tuberculosis. Current Eye Research, v. 42, n. 7, p. 1029-1034, 2017.

VAEDE, D. et al. [Preservatives in eye drops: toward awareness of their toxicity]. Journal francais d'ophtalmologie, v.33, n.7, set. 2010.United States

VELKOV, T. et al. Pharmacology of polymyxins: new insights into an 'old' class of antibiotics. Future Microbiology, v. 8, n. 6, p. 711-724, 2013.

VELKOV, T. et al. Structure activity relationships of polymyxin antibiotics. Journal of Medicinal Chemistry, v. 53, n. 5, p. 1898 - 1916, 2010.

WADHWA, S. et al. Hyaluronic acid modified chitosan nanoparticles for effective management of glaucoma: development, characterization, and evaluation. Journal of Drug Targeting, v. 18, n. 4, p. 292-302, 2010.

WANG, L.-Y. et. al. Preparation of uniform sized chitosan microspheres by membrane emulsification technique and application as a carrier of protein drug. Journal of Controlled Release, v. 106, n. 1-2, p. 62-75, 2005.

WORLD HEALTH ORGANIZATION. Global Tuberculosis Report. 2016. Disponível em: http://apps.who.int/iris/bitstream/10665/250441/1/9789241565394-eng.pdf>. Acesso em: 03 de abr. de 2017.

WORLD HEALTH ORGANIZATION. The top 10 causes of death. 2017. Disponível em: <http://www.who.int/mediacentre/factsheets/fs310/en/>. Acesso em: 27 de mar. de 2017.

WORLD HEALTH ORGANIZATION. Treatment of Tuberculosis Guidelines4th edition, Geneva, 2010.2 Disponível em: $<$ http://apps.who.int/iris/bitstream/10665/44165/1/9789241547833_eng.pdf?ua= 1\&ua=1>. Acesso em: 9 set. 2017.

WORLD HEALTH ORGANIZATION. Vision impairment and blindness. 2017. Disponível em: <http://www.who.int/mediacentre/factsheets/fs282/en/>. Acesso em: 27 de novembro de 2017. 
XIN, J. et al. A novel eye drop of alpha tocopherol to prevent ocular oxidant damage: improve the stability and ocular efficacy. Drug Development and Industrial Pharmacy, v.42, n.4, 2016.

YOSHIHARA E.; NAKAE T. Cytolytic activity of liposomes containing stearylamine. Biochimica et Biophysica Acta, v.854, n. 1, p. 93-101, 1986.

$\mathrm{YU}$, Z. et al. Antibacterial Mechanisms of Polymyxin and Bacterial Resistance. BioMed Research International, v. 2015, 2015.

YUKUYAMA, M.N. et al. Challenges and Future Prospects of Nanoemulsion as a Drug Delivery System. Current Pharmaceutical Design, v. 23, n. 3, p. 495508, 2017.

YUKUYAMA, M.N. et al. Nanoemulsion: process selection and application in cosmetics--a review. International Journal of Cosmetic Science, v.38, n. 1, p. 13-24, fev. 2016.

ZHANG, R. Analysis of polysorbate 80 and its related compounds by RP-HPLC with ELSD and MS detection. Journal of Chromatographic Science, v.50, n.7, p. 598-607, ago. 2012.

ZHANG, Y. The magic bullets and tuberculosis drug targets. Annual Review Pharmacology Toxicology, v. 45, n. 2, p. 529-564, fev. 2005.

ZHANG, Z. et al. Could high-concentration rifampicin kill rifampicin-resistant M. tuberculosis? Rifampicin MIC test in rifampicin-resistant isolates from patients with osteoarticular tuberculosis. Journal of Orthopaedic Surgery and Research, v.9, 2014.

ZHOU, L. et al. In-depth analysis of the human tear proteome. Journal of Proteomics, v. 2012, n.13, jul. p. 3877-3885.

ZHU, X. et al. Synthesis of thiolated chitosan and preparation nanoparticles with sodium alginate for ocular drug delivery. Molecular Vision, v. 18, p. 1973- 1982, 2012. 